\title{
Imaging Fluid Flow in Geothermal Wells Using Distributed Thermal Perturbation Sensing
}

Barry Freifeld and Stefan Finsterle

Earth Sciences Division

Lawrence Berkeley National Laboratory

University of California

Berkeley, CA 94720

December 10, 2010

This work was supported by the Assistant Secretary for Energy Efficiency and Renewable Energy, Geothermal Technologies Program, of the U.S. Department of Energy under Contract No. DE-AC02-05CH11231. 


\section{DISCLAIMER}

This document was prepared as an account of work sponsored by the United States Government. While this document is believed to contain correct information, neither the United States Government nor any agency thereof, nor The Regents of the University of California, nor any of their employees, makes any warranty, express or implied, or assumes any legal responsibility for the accuracy, completeness, or usefulness of any information, apparatus, product, or process disclosed, or represents that its use would not infringe privately owned rights. Reference herein to any specific commercial product, process, or service by its trade name, trademark, manufacturer, or otherwise, does not necessarily constitute or imply its endorsement, recommendation, or favoring by the United States Government or any agency thereof, or The Regents of the University of California. The views and opinions of authors expressed herein do not necessarily state or reflect those of the United States Government or any agency thereof, or The Regents of the University of California.

Ernest Orlando Lawrence Berkeley National Laboratory is an equal opportunity employer. 


\title{
Imaging Fluid Flow in Geothermal Wells Using \\ Distributed Thermal Perturbation Sensing
}

\author{
Barry Freifeld and Stefan Finsterle
}

Earth Sciences Divisions, Lawrence Berkeley National Laboratory

\author{
Status Report on Task 2: \\ Development of Analysis Method for \\ Thermal Conductivity Estimation
}

December 10, 2010

\section{Introduction}

The objective of Task 2 is to develop a numerical method for the efficient and accurate analysis of distributed thermal perturbation sensing (DTPS) data for (1) imaging flow profiles and (2) in situ determination of thermal conductivities and heat fluxes. Numerical forward and inverse modeling is employed to:

(1) Examine heat and fluid flow processes near a geothermal well under heating and cooling conditions.

(2) Demonstrate ability to interpret DTPS thermal profiles with acceptable estimation uncertainty using inverse modeling of synthetic temperature data.

(3) Develop template model and analysis procedure for the inversion of temperature data collected during a thermal perturbation test using fiber-optic distributed temperature sensors.

This status report summarizes initial model developments and analyses.

\section{Model Development}

A numerical model was developed to simulate radial fluid and heat flow in a layered formation around a well, with flow in the wellbore approximated by Darcy's law. The well configuration (Figure 1 and Table 1), stratigraphy, and temperature conditions (Figure 2) are similar to those of Well RRG-9, which is targeted for a hydraulic or hybrid thermo-hydraulic stimulation test at the Raft River Geothermal Field, Idaho (Moore, 2009).

The simulation includes two thermal perturbation tests conducted before and after the formation is fractured using conventional or thermal-hydraulic stimulation for the development of an enhanced geothermal system. During the simulated thermal perturbation test, heat is applied at a rate of $20 \mathrm{~W} / \mathrm{m}$ along the well axis for 100 hours; temperature profiles are recorded during the subsequent 100-hour cooling period using a 
distributed temperature sensor (DTS) at high spatial and temporal resolution. During the test, the well is produced at a constant rate of $1 \mathrm{~kg} / \mathrm{s}$. The same distributed thermal perturbation test is repeated following a 200-hour period during which the permeabilities of the Elba Quartzite or the Lower Narrow Schist layers are increased by several orders of magnitude (the stimulation itself is not modeled explicitly, but represented by an instantaneous permeability increase, followed by a thermal and hydrologic recovery period). The formation parameters are listed in Table 2. Figure 3 illustrates the test sequence and simulated temperature data, which are perturbed using random noise with a standard deviation of $0.1^{\circ} \mathrm{C}$. (We consider a spatial resolution of $10 \mathrm{~m}$ and a temporal resolution of $2 \mathrm{~h}$, which is substantially lower than what can be achieved by DTS measurements.)

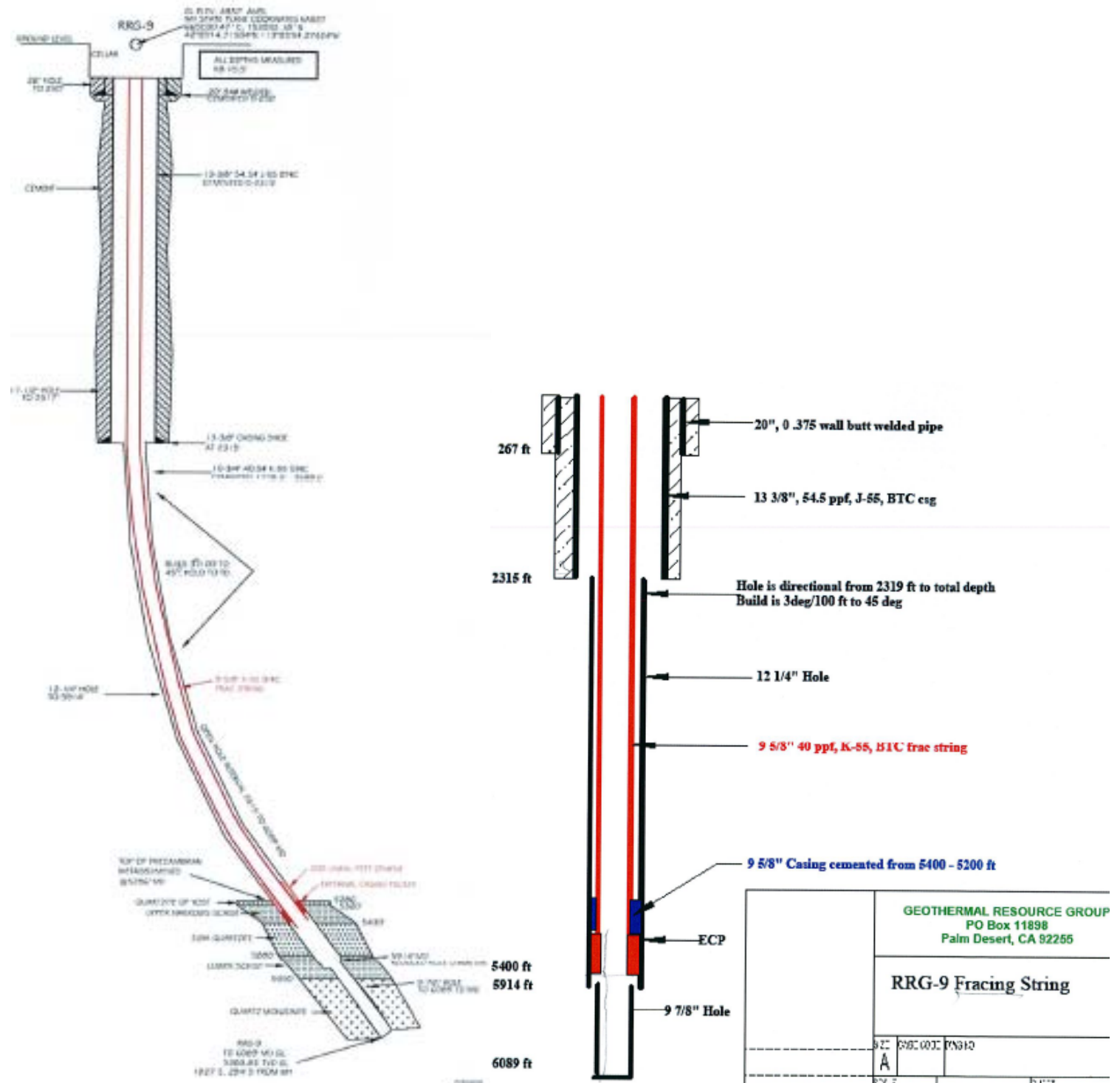

(a)

(b)

Figure 1. (a) Current and proposed casing plan for Well RRG-9. The well is currently uncased below $2315 \mathrm{ft}$. The proposed casing is shown in red. (b) Casing plan for hydrofracing Well RR-9 (Moore, 2009). 

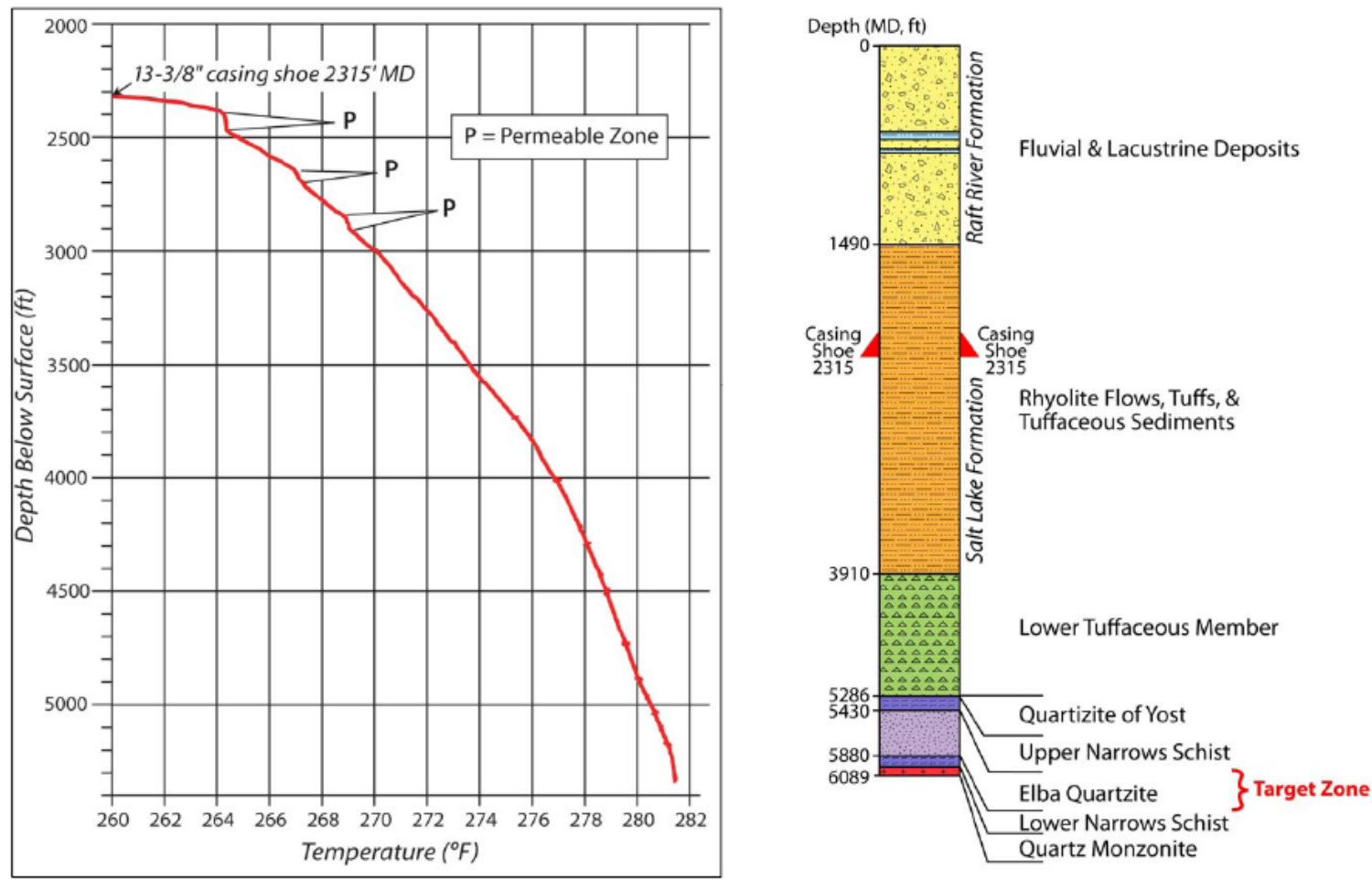

Figure 2. Stratigraphy and temperatures encountered in Well RRG-9. Depths shown are true vertical depths (Moore, 2009).

Table 1. Modeled wellbore configuration and stratigraphy. The well deviates with an inclination of $44^{\circ}$.

\begin{tabular}{|c|c|c|c|c|}
\hline $\begin{array}{l}\text { Measured } \\
\text { Depth } \\
\text { [ft] } \\
\text { [m] }\end{array}$ & $\begin{array}{c}\text { Depth Below } \\
\text { Surface } \\
{[\mathrm{ft}]} \\
{[\mathrm{m}]}\end{array}$ & $\begin{array}{c}\text { Well Radius } \\
\text { [inch] } \\
\text { [cm] }\end{array}$ & $\begin{array}{c}\text { Temperature } \\
{\left[{ }^{\circ} \mathbf{F}\right]} \\
{\left[{ }^{\circ} \mathbf{C}\right]}\end{array}$ & Stratigraphic Unit \\
\hline 5400.0 & 4888.4 & \multirow{5}{*}{$\begin{array}{l}12.25 \\
15.56\end{array}$} & 280.0 & $\begin{array}{c}\text { Upper Narrows } \\
\text { Schist }\end{array}$ \\
\hline $\begin{array}{l}1627.6 \\
54300\end{array}$ & $\begin{array}{l}1473.4 \\
4909.9\end{array}$ & & & \multirow{2}{*}{ Elba Quartzite } \\
\hline 1636.6 & 1479.9 & & & \\
\hline 5880.0 & 5233.7 & & & \multirow{4}{*}{$\begin{array}{c}\text { Lower Narrows } \\
\text { Schist }\end{array}$} \\
\hline 1772.2 & 1577.4 & & & \\
\hline 5914.0 & 5258.1 & \multirow{4}{*}{$\begin{array}{l}9.875 \\
12.54\end{array}$} & & \\
\hline 1782.5 & 1584.8 & & & \\
\hline 5990.0 & 5312.8 & & & \multirow[t]{4}{*}{ Quartz Monsonite } \\
\hline 1805.4 & 1601.3 & & & \\
\hline 6089.0 & 5384.0 & bottom of & 281.9 & \\
\hline 1835.2 & 1622.7 & well & 138.8 & \\
\hline
\end{tabular}


Table 2. Formation properties

\begin{tabular}{|c|c|c|}
\hline Parameter & Value & $\begin{array}{c}\text { Variation for } \\
\text { Sensitivity } \\
\text { Analysis }\end{array}$ \\
\hline Porosity (all units), $\phi$ & 0.05 & $\mathrm{n} / \mathrm{a}$ \\
\hline \multicolumn{3}{|c|}{ Upper Narrow Schist } \\
\hline Permeability, $\log \left(k_{U N S}\left[\mathrm{~m}^{2}\right]\right)$ & -16.0 & 1.0 \\
\hline Thermal conductivity, $\lambda_{U N S}\left[\mathrm{~W} \mathrm{~m}^{-1} \mathrm{~K}^{-1}\right]$ & 3.0 & 0.5 \\
\hline \multicolumn{3}{|c|}{ Elba Quartzite } \\
\hline Permeability, $\log \left(k_{E Q b}\left[\mathrm{~m}^{2}\right]\right)$ before fracing & -15.0 & 1.0 \\
\hline Permeability, $\log \left(k_{E Q a}\left[\mathrm{~m}^{2}\right]\right)$ after fracing & -11.0 & 1.0 \\
\hline Thermal conductivity, $\lambda_{E Q}\left[\mathrm{~W} \mathrm{~m}^{-1} \mathrm{~K}^{-1}\right]$ & 4.0 & 0.5 \\
\hline \multicolumn{3}{|c|}{$\begin{array}{l}\text { Lower Narrows Schist } \\
\end{array}$} \\
\hline Permeability, $\log \left(k_{L N S b}\left[\mathrm{~m}^{2}\right]\right)$ before fracing & -16.0 & 1.0 \\
\hline Permeability, $\log \left(k_{L N S a}\left[\mathrm{~m}^{2}\right]\right)$ after fracing & -13.0 & 1.0 \\
\hline Thermal conductivity, $\lambda_{L N S}\left[\mathrm{~W} \mathrm{~m}^{-1} \mathrm{~K}^{-1}\right]$ & 3.0 & 0.5 \\
\hline \multicolumn{3}{|c|}{ Quartz Monsonite } \\
\hline Permeability, $\log \left(k_{Q M}\left[\mathrm{~m}^{2}\right]\right)$ & -14.0 & 1.0 \\
\hline Thermal conductivity, $\lambda_{Q M}\left[\mathrm{~W} \mathrm{~m}^{-1} \mathrm{~K}^{-1}\right]$ & 5.0 & 1.0 \\
\hline
\end{tabular}

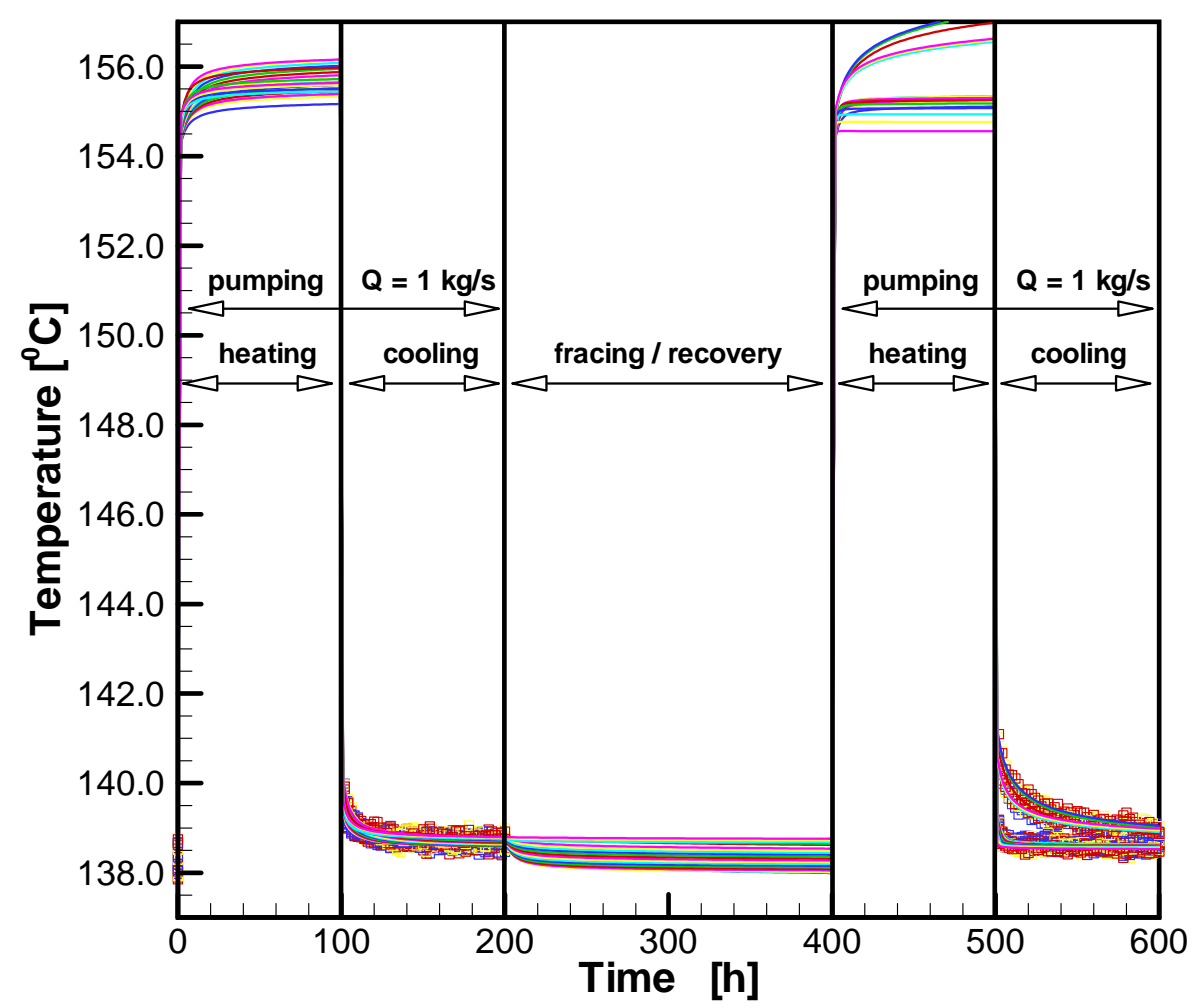

Figure 3. Simulated thermal perturbation tests performed before and after hydraulic fracturing. Temperature data during cooling period (see also Figure 6 and Figure 7 below) are used for estimation of thermal and hydrologic parameters. 


\section{Results}

\subsection{Forward Simulations}

Two simulations of the test sequence shown in Figure 3 were performed. The first modeling run assumes that the Elba Quartzite layer is fractured during stimulation, increasing its permeability by four orders of magnitude; the second run assumes that the Lower Narrow Schist is the weakest layer; it is fractured, and its permeability is increased by three orders of magnitude.

Figure 4 and Figure 5 show the temperature distributions around the borehole at the beginning, middle, and end of the cooling periods for both thermal perturbation tests, i.e., before and after fracing the Elba Quartzite and Lower Narrows Schist layers, respectively. The temperature distribution after heating is affected by (1) the initial geothermal gradient (a very minor effect in this short monitoring interval), (2) the thermal properties of the individual layers, and (3) the hydrologic properties of the layers, as they govern (a) fluid mixing and heat flow distribution within the flowing well, and (b) the convective heat transport towards the well induced by pumping. Moreover, the temperature recorded by the distributed temperature sensor (DTS) in the well is a convolution of the heat fluxes into the well as water moves upwards, with inflow points determined by the permeability distribution, and heat flow determined by both flow volume and the temperature distribution in the formation surrounding the well.

This sensitivity of the temperature distribution in the formation and along the well profile with respect to permeability is the basis for detecting fluid inflow and thus fracing locations by means of thermal perturbation tests with DTS measurements. It is visualized by comparing the left and right columns of Figure 4 and Figure 5, as well as the temperature transients shown in Figure 6 and Figure 7. Increasing the permeability by fracing leads to a noticeable cooling effect as more relatively cold formation water (farfield water less affected by the heating) is produced from the high-permeability layer. In addition, the well section below the fractured layers has a substantially smaller contribution to the total pumping rate (due to wellbore hydraulics), leading to a more stable, more uniform, conduction-dominated heat transfer and generally higher temperatures. This is best seen in Figure 5, where fracing of the initially low-permeability schist creates a distinct temperature anomaly indicating an inflow point at the interface between the Lower Narrows Schist and the Elba Quartzite layers.

The inflow pattern has a corresponding thermal signature, which is picked up by the high-resolution DTS measurements. Synthetic DTS measurements are shown in Figure 6 and Figure 7 for the two fracing scenarios. The temperature transients for the first, prestimulation thermal perturbation tests are identical; those for the post-stimulation tests are distinctly different, with higher temperatures at sensor locations below the elevation where fracing occurred, and relatively colder temperatures at and above that location.

Sensitivity analyses and inversions need to be performed to see whether high-resolution temperature data are sufficient to identify thermal and hydrological properties of the formation. These analyses are presented below. 
First Thermal Perturbation Test Before Fracturing
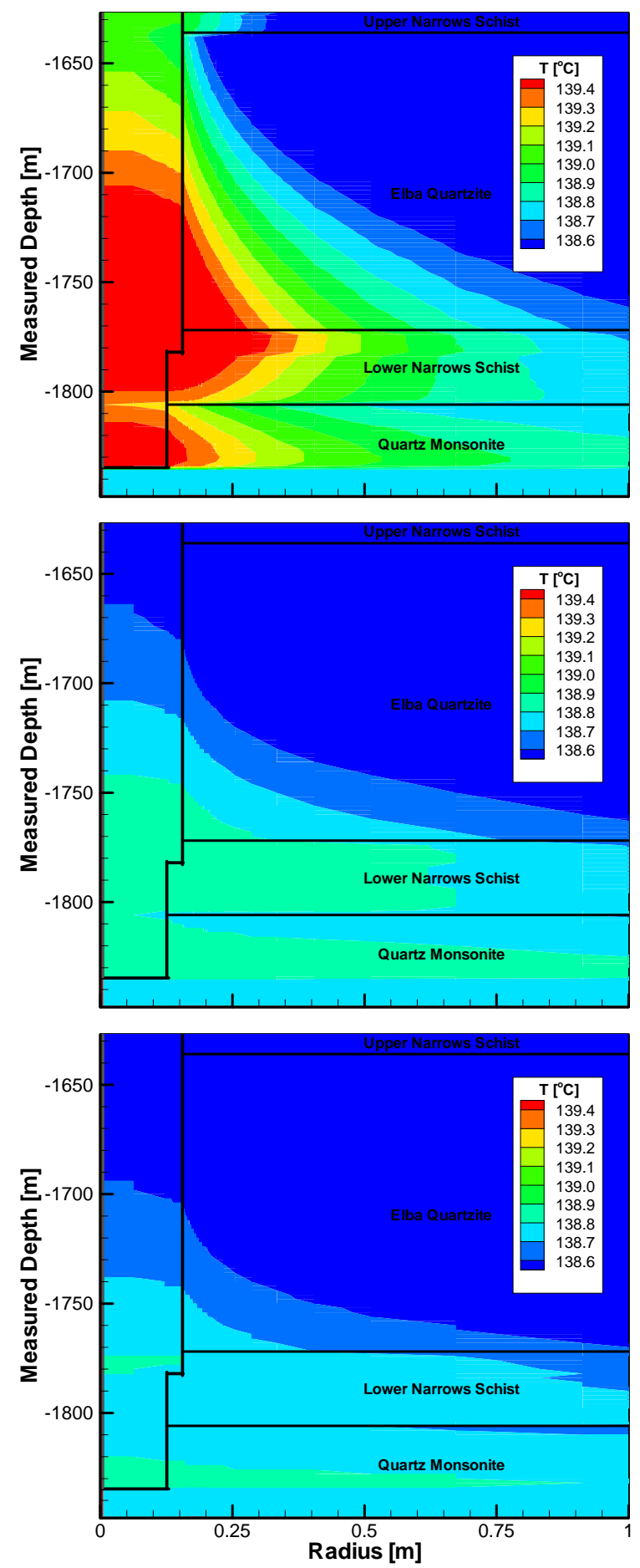

Second Thermal Perturbation Test After Fracturing of Elba Quartzite
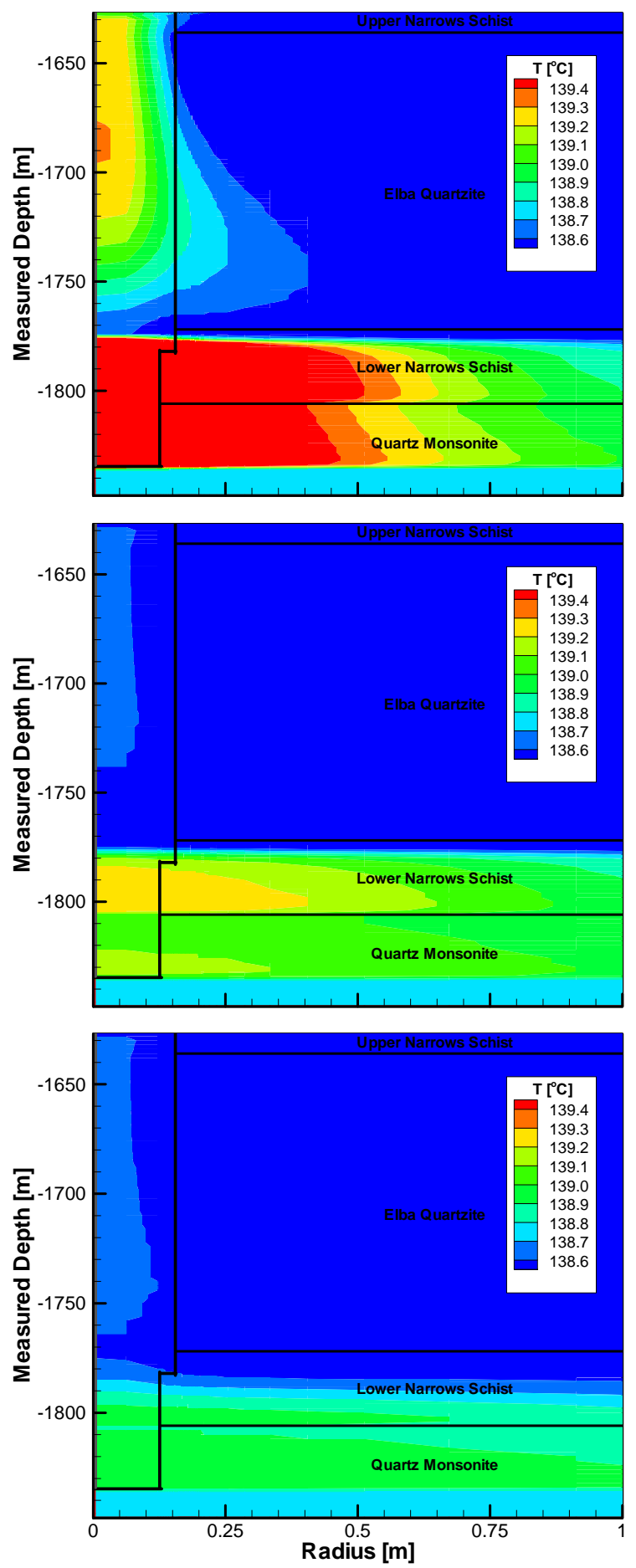

Figure 4. Temperature distribution during a thermal perturbation test performed before (left column) and after (right column) hydrofracing of the Elba Quartzite at the beginning of the cooling period (top row), after 50 hours (middle row), and after 100 hours (bottom row). 
First Thermal Perturbation Test Before Fracturing
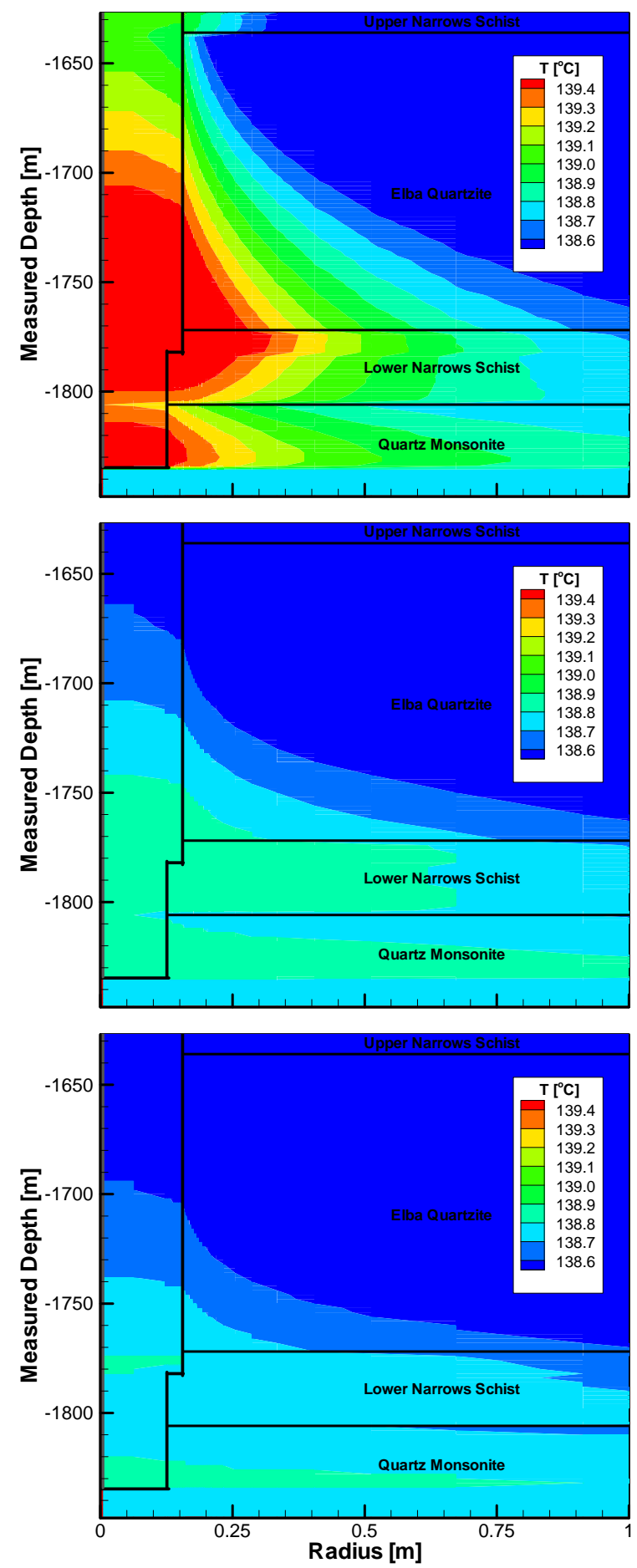

Second Thermal Perturbation Test After Fracturing of Lower Narrows Schist
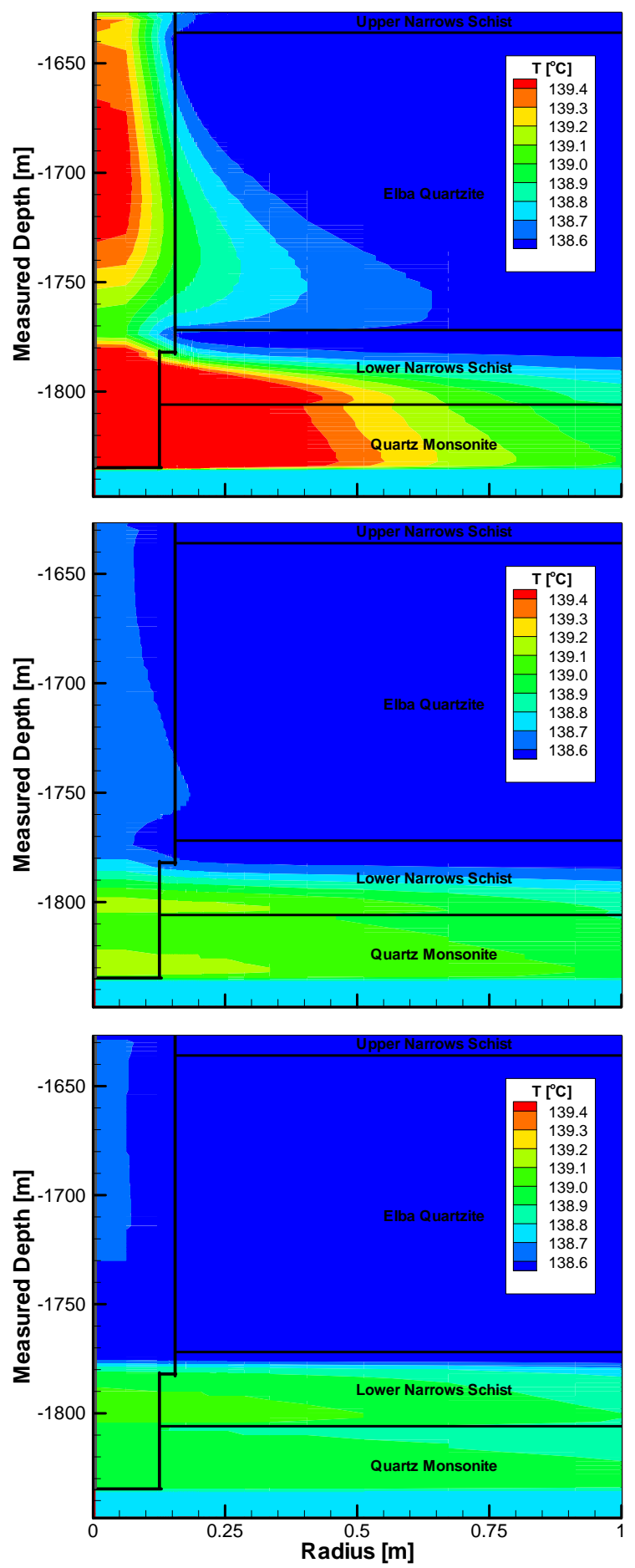

Figure 5. Temperature distribution during a thermal perturbation test performed before (left column) and after (right column) hydrofracing of the Lower Narrows Schist at the beginning of the cooling period (top row), after 50 hours (middle row), and after 100 hours (bottom row). 


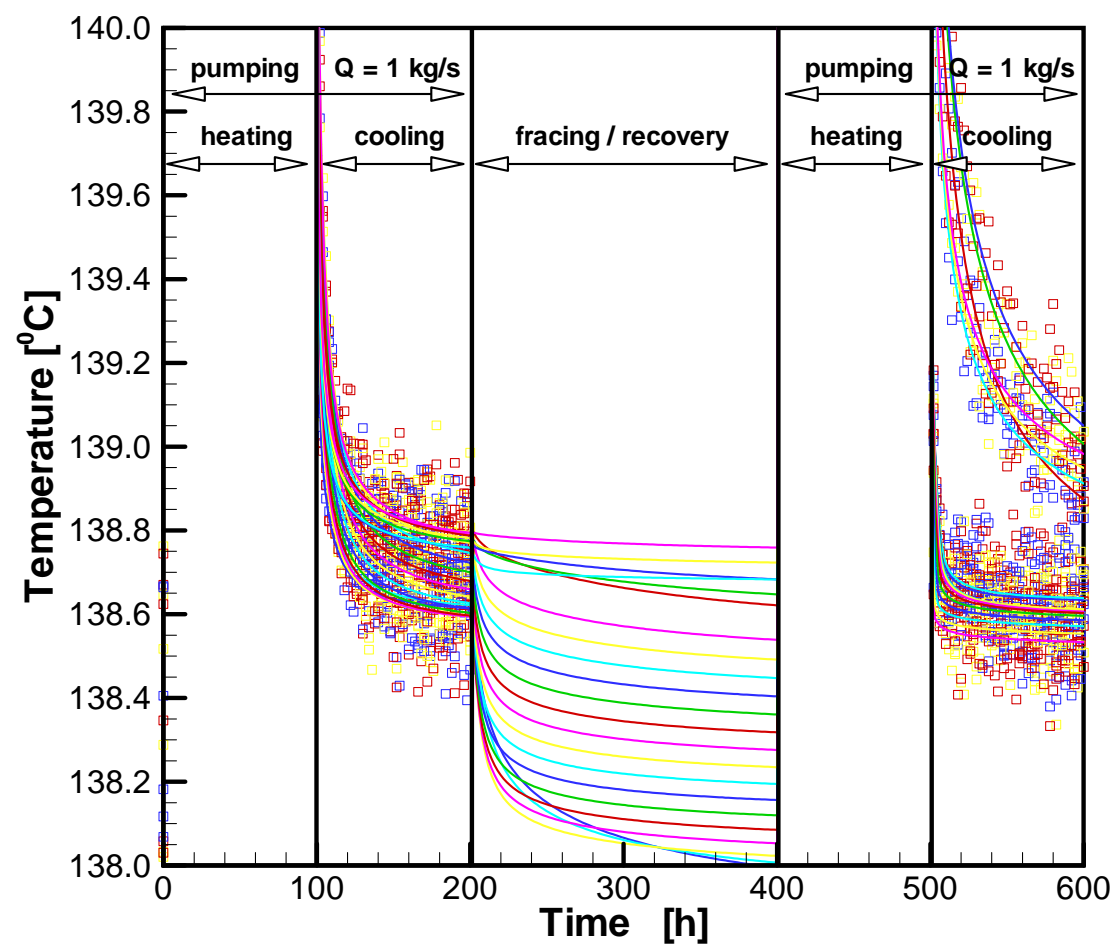

Figure 6. Simulated thermal perturbation tests performed before and after hydraulic fracturing of the Elba Quartzite unit. Temperature data during cooling period are used for estimation of thermal and hydrologic parameters.

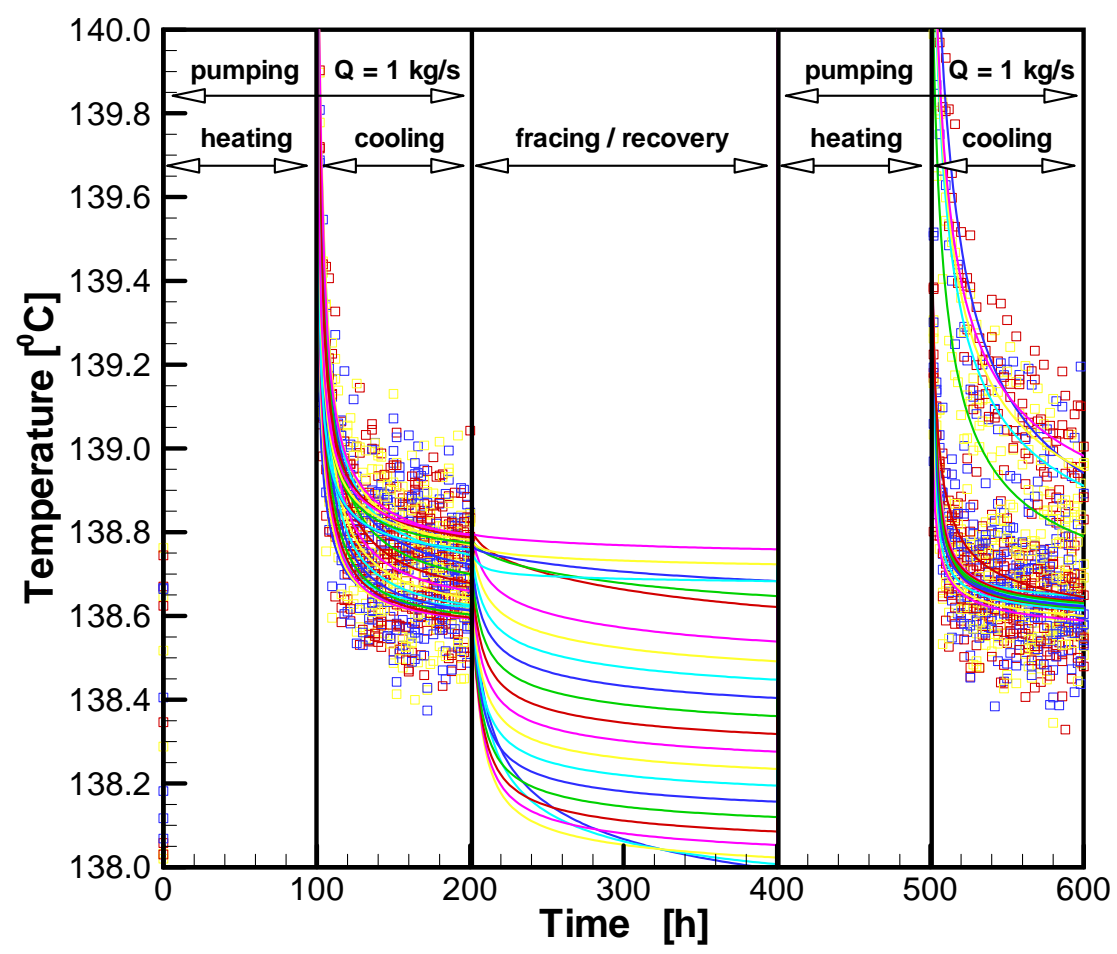

Figure 7. Simulated thermal perturbation tests performed before and after hydraulic fracturing of the Lower Narrows Schist unit. Temperature data during cooling period are used for estimation of thermal and hydrologic parameters. 


\subsection{Sensitivity Analysis}

A necessary condition for inferring properties from measured DTS data is that the simulated temperatures are sensitive to changes in the thermal and hydrologic parameters of interest. To compare parameters of different type (and different units), the local sensitivity coefficients are scaled by an expected variation of each parameter (see Table 2). The coefficients are also scaled by the inverse of the assumed measurement error (here, $0.1^{\circ} \mathrm{C}$ ). This scaling leads to dimensionless, comparable sensitivity coefficients.

Figure 8 shows the time-dependent sensitivity coefficients of temperature measured in the middle of the Elba Quartzite unit with respect to five hydrological and four thermal properties as well as the total sensitivity, which is the sum of the absolute sensitivity coefficients at a given point in time. A negative sensitivity coefficient indicates that increasing the corresponding parameter leads to a reduced temperature.

During the first, pre-stimulation test, the permeability of the Quartz Monsonite has a significant impact on the temperature recorded at a measured depth of $-1700 \mathrm{~m}$, even though this layer is only penetrated over a short distance. The reason for this high sensitivity is this layer's high permeability and the fact that it is at the bottom of the well, i.e., a comparatively high influx of relatively cold water (see top left panel of Figure 4) leads to a temperature reduction throughout the monitored well interval. The dominant impact of the Quartz Monsonite on measured temperatures at a depth of $-1700 \mathrm{~m}$ disappears completely for the second, post-stimulation thermal perturbation test, because the fractured Elba Quartzite is now providing the majority of the fluid to the well, whereas the lower part of the well is essentially stagnant. Note that temperature measurements near the bottom of the well (not shown) remain sensitive (with a positive sensitivity coefficient with respect to Elba Quartzite permeability), thus providing valuable information for the estimation of thermal and hydrological parameters.

The sensitivity of the Elba Quartzite permeability is relatively high due to the thickness of this layer. It prevails throughout the duration of the first test (with positive values at early times, reflecting the fast inflow of heated water, followed by negative coefficients of increasing magnitude as cooled water from the far field is more quickly drawn into the well as the permeability is increased). Its impact, however, is much shorter for the second test, as the high permeability of the fractured unit results in a quick stabilization of temperatures to pre-test conditions.

Figure 9 shows the total sensitivity (the sum of the absolute values of the sensitivity coefficients for all parameters) as a function of time for all sensors. This plot indicates the overall contribution of a temperature measurement (in space and time) to the estimation of all parameters. The pre-stimulation thermal perturbation test has generally a higher information content compared to the post-stimulation test, because the significantly increased permeability of the fractured Elba Quartzite leads to shorter transients. However, early-time data at the beginning of the cooling period of the second test show high overall sensitivity. Figure 9 suggests that shortening the test duration (to about 50 hours) would not lead to a substantial loss of information, and the parameters of interest could be estimated with similar uncertainty, even though sensitivities start to increase slightly towards the end of the testing period, which is mainly a result of the increasing sensitivity of the Elba Quartzite permeability with time, as seen in Figure 8. 


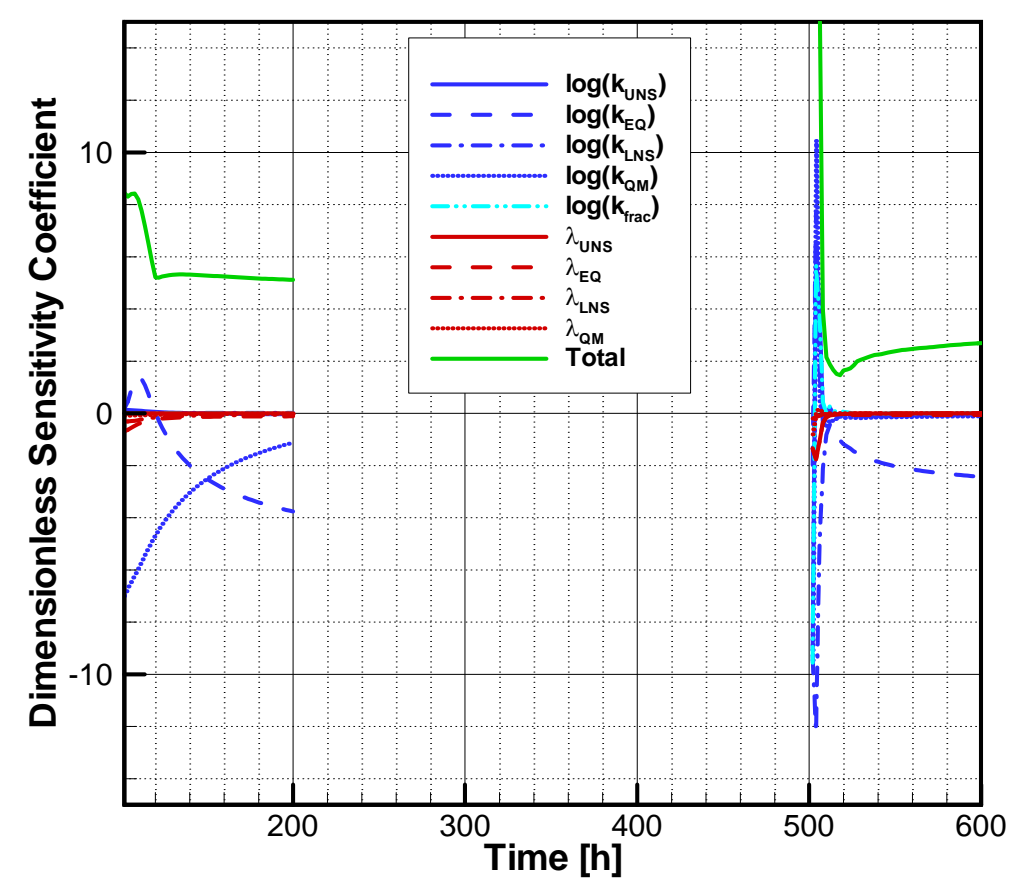

Figure 8. Sensitivity of DTS measurements in the middle of the Elba Quartzite unit to hydrological and thermal parameters.

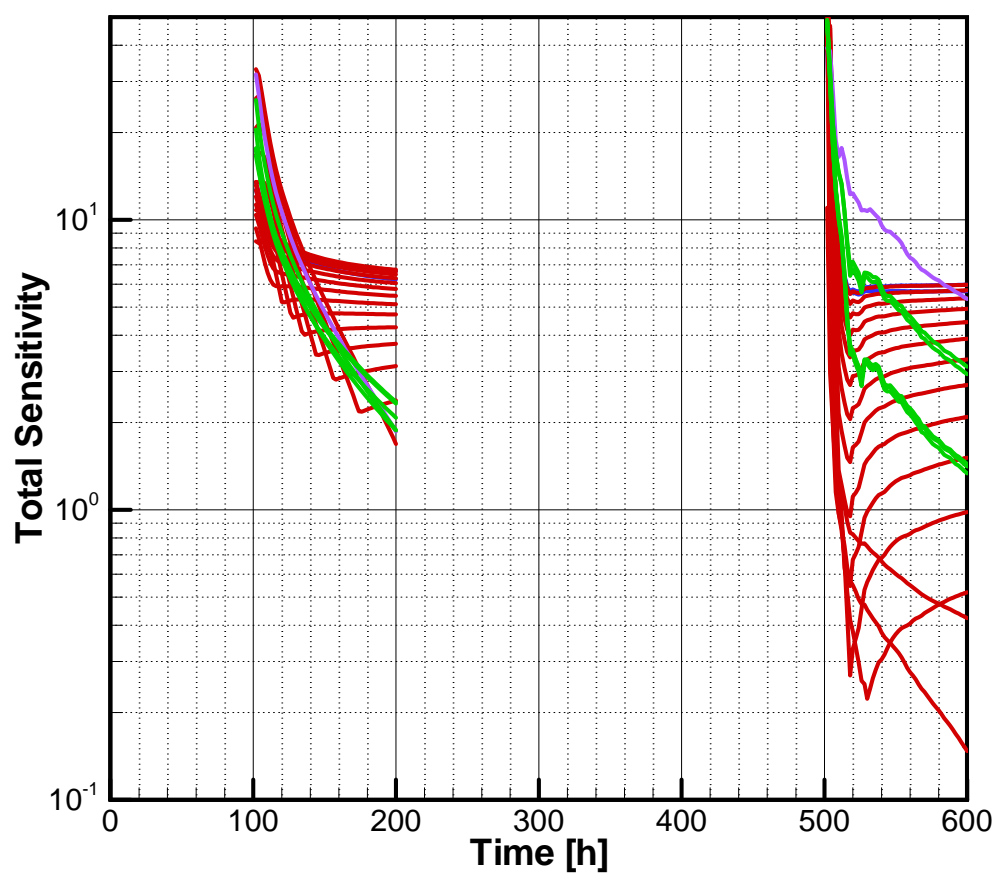

Figure 9. Total sensitivity of all temperature measurements along the DTS with respect to all parameters as a function of time. Sensor locations: blue: Upper Narrows Schist; red: Elba Quartzite, purple: Lower Narrows Schist; green: Quartz Monsonite. 


\subsection{Inverse Analysis}

High sensitivity and low measurement noise are necessary, but not sufficient conditions for the determination of parameters with acceptably low estimation uncertainties. Strong correlations among the parameters may lead to an ill-posed inverse problem, where changing one parameter can be partly compensated by a change in another parameter, leading to a similar temperature response that prevents unique identification of the parameters. To examine parameter correlations and resulting estimation uncertainties, synthetic inversions are performed, where the temperature data as shown in Figure 6 and Figure 7 are used to estimate hydrological and thermal properties. Under a linearity and normality assumption, the covariance matrix of the estimated parameters can be calculated based on the sensitivity coefficients and the assumed size of the measurement errors. The covariance matrix contains the estimation uncertainties on its diagonal; its off-diagonal terms can be used to calculate correlation coefficients. A scaled measure of overall correlation is also calculated, with a value close to one indicating the parameter can be estimated independently from other parameters, and a value close to zero indicating strong overall correlations. The total sensitivity is the sum of all absolute values of the sensitivity coefficients. 
Table 3 and Table 4 show the estimation uncertainties of all parameters for the two fracing scenarios, along with the overall correlation and total sensitivity measure. It is apparent that the properties of the Upper Narrows Schist cannot be estimated, as only a short section of this unit is exposed to the well, with a single temperature sensor collecting data exposed to water that enters the well from this unit. The resulting estimation uncertainty is mainly a result of low overall sensitivity.

The hydrologic and thermal properties of the Elba Quartzite layer are accurately estimated. The thermal conductivity of this layer affects the temperature distribution over most of the monitored section during both the first and second thermal perturbation test, explaining its high overall sensitivity. Both the pre- and post-stimulation permeabilities can be determined, suggesting that thermal perturbation testing combined with highresolution temperature sensing is a viable means to detect changes in inflow patterns caused by fracing.

The low-permeability Lower Narrows Schist layer has a minor contribution of the fluids flowing up the well, and has thus low overall sensitivity and correspondingly high estimation uncertainties. The Quartz Monsonite layer, by contrast, has the highest prestimulation permeability, and thus relatively high sensitivity and low estimation uncertainty.

A similar analysis can be performed for fracing of the Lower Narrows Schist. As Table 4 reveals, the actual results are considerably different from the scenario in which the permeability of the Elba Quartzite is increased due to stimulation. Inflow patterns and convolution of temperature signals are significantly different, resulting in different sensitivities and correlations. While the pre-stimulation permeability of the Lower Narrows Schist cannot be determined (due to its low permeability), the inversion of temperature data would clearly show the existence of a feed zone after stimulation, and would be able to estimate its permeability with acceptably low estimation uncertainty. 
Table 3. Estimation uncertainties for fracing of Elba Quartzite

\begin{tabular}{|l|r|r|r|r|}
\hline Parameter & Value & Uncertainty & Correlation & Sensitivity \\
\hline \multicolumn{5}{|c|}{ Upper Narrow Schist } \\
\hline Permeability, $\log \left(k_{U N S}\right)$ & -16.0 & 0.86 & 0.33 & 0.04 \\
\hline Thermal conductivity, $\lambda_{U N S}$ & 3.0 & 6.18 & 0.64 & 0.03 \\
\hline \multicolumn{5}{|c|}{ Elba Quartzite } \\
\hline Permeability, $\log \left(k_{E Q b}\right)$ before fracing & -15.0 & 0.02 & 0.38 & 1.88 \\
\hline Permeability, $\log \left(k_{E Q a}\right)$ after fracing & -11.0 & 0.11 & 0.83 & 1.29 \\
\hline Thermal conductivity, $\lambda_{E Q}$ & 4.0 & 0.06 & 0.83 & 3.92 \\
\hline \multicolumn{7}{|c|}{ Lower Narrows Schist } \\
\hline Permeability, $\log \left(k_{L N S}\right)$ & -16.0 & 0.79 & 0.85 & 0.06 \\
\hline Thermal conductivity, $\lambda_{L N S}$ & 3.0 & 0.32 & 0.76 & 0.02 \\
\hline \multicolumn{7}{|c|}{ Quartz Monsonite } \\
\hline Permeability, $\log \left(k_{Q M}\right)$ & -14.0 & 0.08 & 0.70 & 0.28 \\
\hline Thermal conductivity, $\lambda_{Q M}$ & 5.0 & 0.09 & 0.97 & 1.57 \\
\hline
\end{tabular}

Table 4. Estimation uncertainties for fracing of Lower Narrows Schist

\begin{tabular}{|l|r|r|r|r|}
\hline Parameter & Value & Uncertainty & Correlation & Sensitivity \\
\hline \multicolumn{5}{|c|}{ Upper Narrow Schist } \\
\hline Permeability, $\log \left(k_{U N S}\right)$ & -16.0 & 1.10 & 0.25 & 0.02 \\
\hline Thermal conductivity, $\lambda_{\text {UNS }}$ & 3.0 & 7.20 & 0.54 & 0.04 \\
\hline \multicolumn{5}{|c|}{ Elba Quartzite } \\
\hline Permeability, $\log \left(k_{E Q}\right)$ & -15.0 & 0.03 & 0.24 & 1.18 \\
\hline Thermal conductivity, $\lambda_{E Q}$ & 4.0 & 0.39 & 0.43 & 0.61 \\
\hline \multicolumn{5}{|c|}{ Narrows Schist } \\
\hline Permeability, $\log \left(k_{L N S}\right)$ before fracing & -16.0 & 0.89 & 0.74 & 0.01 \\
\hline Permeability, $\log \left(k_{L N S a}\right)$ after fracing & -11.0 & 0.05 & 0.40 & 0.94 \\
\hline Thermal conductivity, $\lambda_{L N S}$ & 3.0 & 0.20 & 0.35 & 2.35 \\
\hline & Quartz Monsonite \\
\hline Permeability, $\log \left(k_{Q M}\right)$ & -14.0 & 0.08 & 0.77 & 0.07 \\
\hline Thermal conductivity, $\lambda_{Q M}$ & 5.0 & 0.09 & 0.97 & 1.86 \\
\hline
\end{tabular}




\section{Concluding Remarks}

Numerical forward in inverse modeling calculations were performed to examine the ability of thermal perturbation tests with high-resolution distributed temperature sensor measurements to estimate hydrologic and thermal properties of a formation targeted for EGS development.

The penetration of heat into the formation during the heating period, and the observable temperature decline during the cooling period depends on rather complex interactions between thermal and hydrologic formation properties. This coupling of fluid and heat flow, and the sequential mixing of fluids with different temperatures within the flowing well, leads to an intricate temperature signal that is recorded with high spatial and temporal resolution by the DTS. The actual temperature profile is strongly affected not only by the inflow of fluid at the corresponding elevation, but by the upstream and downstream conditions. This leads to some averaging and increase in correlation, but at the same time broadens the data basis that can be used to estimate a parameter of interest. For example, all temperatures measured below the weakest layer that is fractured during stimulation tend do be higher compared to the pre-stimulation profile. The degree of this change depends on the permeability increase caused by hydraulic or thermal-hydraulic stimulation. Since thermal properties are likely to change much less than hydrologic properties during fracing, the change in permeability can be determined with acceptable estimation uncertainty.

Two scenarios were considered, with the Elba Quartzite unit and the Lower Narrows Schist unit assumed to fracture during stimulation. The resulting temperature transients as well as the sensitivities and estimation uncertainties vary considerably for these two scenarios, as expected. It is therefore not possible to predict the accuracy with which a given parameter can be estimated. However, the simulations and inversions suggest that the thermal perturbation tests with high-resolution temperature measurements have the potential to determine the location of feed zones and their post-stimulation properties. Hydrologic parameters - and their changes during fracing — can also be identified, andto a lesser degree- the thermal properties.

These preliminary conclusions are based on the assumed well configuration, formation properties, and testing parameters. The latter may be tailored to improve the identifiability of a specific parameter of interest, e.g., by changing the pumping rate, heat input, and test duration.

A detailed design and optimization of the thermal perturbation test will be performed prior to a field test at a specific site.

\section{References}

Moore, J., Concept Testing and Development at the Raft River Geothermal Field, Idaho, DE-EE0000215, $1^{\text {st }}$ Quarter 2010 Technical Report, December 31, 2009. 